\title{
Polarization and clustering in scientific debates and problem framing: network analysis of the science-policy interface for grassland management in China
}

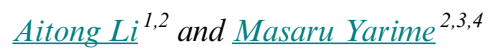

\begin{abstract}
Environmental problems are usually framed by a repertoire of arguments articulated by a network of individuals (scientists and policymakers) and their affiliated institutions. Given the complexity of this network, it is important to conduct network analyses on both individual and organizational levels to achieve a better understanding of the underlying political structure that influences science-policy communication. Through an empirical study of a policy network related to grassland management in China, our study examines the underlying political structure of the network as well as its political impact on the problem-framing processes. The analysis reveals that political polarization and power imbalances in the network, the product of existing institutional arrangements, have confined the framing of environmental problems to specific areas and impeded the development of comprehensive policies.
\end{abstract}

Key Words: environmental management; institutional balance; political polarization; problem framing; science-policy interface; social network analysis

\section{INTRODUCTION}

Searching for solutions always begins with properly framing the problem. Framing is a process that involves narrowing one's focus, selecting and organizing facts and evidence, developing concepts and models, interpreting data, and defining priorities (Entman 1993, Benford and Snow 2000, Nisbet and Mooney 2007). This multistage process, together with the diverse interests that emerge along the way, provides ample space for an array of social and political factors to come into play. Consequently, framing a problem is not just a matter of reaching scientific consensus but "an interplay of scientific discovery and description with other political, economic, and social factors" (Jasanoff and Wynne 1998:4).

Embedded in socio-political contexts, this framing process is closely linked to an extensive network formed at the science-policy interface. Larger than the scientific community alone, this network comprises scientists, policymakers, and other stakeholders (Bäckstrand 2003, Offermans and Glasbergen 2015). It is "a knowledge-based network of individuals with a claim to policy-relevant knowledge based upon common professional beliefs and standards of judgement, and common policy concerns" (Rose 1991:15-16). The knowledge of this group of social actors will influence the problem framing process and the subsequent policy decisions (Kenis and Schneider 1991, Haas 1992). Failing to produce legitimate policy often reflects ineffective communication and political asymmetry rather than simply the lack of credible scientific supports (Stone 2002, Pregernig 2014). Examining the internal organization of this policy network is crucial for understanding power dynamics in problem-framing processes.

When connecting problem-framing processes with a policy network, one must be aware that this policy network develops around existing institutional arrangements that bind individuals and organizations together. This institutional arrangement is often self-sustaining and may create constrains for subsequent development and change (David 1994, Cheon and Urpelainen 2013, Schoon 2013). Various theories of institutional continuity and change have been well discussed in political science and other disciplines; they all seek to explain the underlying political mechanisms that sustain, reinforce, or reproduce institutions' status quo (Pierson 2004, Thelen 2004, Mahoney and Thelen 2009). Pierson (2004:35) notes that institutions "may encourage individuals and organizations to invest in specialized skills, deepen relationships with other individuals and organizations, and develop particular political and social identities." Moreover, actors endowed with more power may use their authority to "increase their own capacities for political action while diminishing those of their rivals" (Pierson 2000:36). This process of political clustering and power disparity is closely related to the development of problem framing. Strong clusters can work to enhance the attractiveness of their own arguments in relation to the alternatives supported by contending groups, complicating the problem-framing processes.

Previous research, however, tends to describe the complex interactions at the science-policy interface in qualitative terms; this method limits these studies' scope of analysis to a few political actors. Moreover, researchers often determine these lists of actors or institutions ahead of time rather than compiling them from real-life data. This approach leaves researchers at risk of overlooking important hidden actors or agencies involved in political decision-making. Given the extensive network behind policymaking processes, incorporating network data is crucial for understanding the complex array of individuals and institutions embedded in scientific discussion and problem-framing processes (Bodin and Crona 2009, Muñoz-Erickson and Cutts 2016).

\footnotetext{
${ }^{1}$ Department of Geography and Resource Management, The Chinese University of Hong Kong, Hong Kong, ${ }^{2}$ Graduate School of Public Policy, The University of Tokyo, Japan, ${ }^{3}$ School of Energy and Environment, City University of Hong Kong, Hong Kong, ${ }^{4}$ Department of Science, Technology, Engineering and Public Policy, University College London, UK
} 
Through an empirical study of grassland management in China, our study illustrates how political polarization and power imbalances in the policy network, resulting from existing institutional arrangements, have constrained the framing of environmental problems and impeded the development of comprehensive policies. Faced with the problems of grassland degradation, policymakers and scientists in China have debated with one another about the root causes of the degradation. Ongoing academic and political debates have led to persistent controversies surrounding the policies of grassland management (Williams 2002, Yeh 2005, Kolås 2014). Thus, the analysis of grassland management in China serves as a typical case study for understanding power dynamics in policy networks and their impact on the framing of environmental problem. In our study, three specific questions are asked: (1) What is the underlying political structure of the policy network? (2) What has given rise to this political structure? (3) How has this political structure influenced the framing of environmental problems?

\section{GRASSLAND MANAGEMENT IN CHINA}

Grasslands cover more than $40 \%$ of the land in China (SBEP 2006). Climate change, population migration, and agricultural expansion have long affected the distribution of grasslands (Wu and Loucks 1992, Ye and Fang 2013). Public concern for this environmental problem has increased in recent years, partially a result of the sandstorms that blanketed the sky of Beijing in the 1990s (Zhang 2012). Most of the sandstorms occurred in the early spring, "blowing from Inner Mongolia (especially Alxa and the eastern grasslands) and northern Hebei into Beijing and Tianjian, and as far as Japan and the Koreas" (Brown et al. 2008:44).

These environmental events provoked mounting public concern for grassland degradation in Inner Mongolia. In response to the public outcry, policymakers and scholars from different disciplines began to discuss the possible root causes of grassland degradation and called for a new level of government intervention. Policymakers who participated in the discussion came mainly from the Ministry of Agriculture, the major government agency overseeing comprehensive grassland management. Scholars who joined the discussion came from various disciplinary backgrounds, including geography, economics, ecology, and anthropology. The participating scholars and policymakers proposed various possible root causes, including overgrazing, climate change, agricultural expansion, mining activities, lack of modernization, and loss of local environmental knowledge. Despite the coexistence of multiple casual explanations, the framing of the problem was eventually narrowed down to few areas.

In the early 2000s, the Chinese government announced the implementation of grazing bans. As indicated by the policy, the government tends to assume that overgrazing is the main cause of grassland degradation. However, some researchers point out that the official overgrazing claim may be based on shaky scientific ground. As noted by Harris (2010), Chinese government's evaluation of grassland condition is rarely subjected to scientific examination. Without standardized definitions and systematic training, "local grassland bureaus" are inclined to classify "areas under their jurisdiction based on superficial and subjective impressions" (Harris 2010:3). This lack of credible statistical data raised the question of the validity of the official overgrazing claim.
Other criticisms of the grazing bans have concentrated on the topdown approaches and the transformation of local herding behaviors toward a more individualized management that considers only short-term economic interests (Dong et al. 2007, $\mathrm{Yu}$ and Farrell 2013). The controversy surrounding the grazing bans remains.

From multifaceted discussions of grassland problems to the official policy targeting overgrazing, ideas were seemingly filtered out during the framing processes through the science-policy interface. What type of forces have determined the flow of ideas among and between scientists and policymakers? Fully understanding the mechanism requires a closer look at the interactions among these actors.

\section{METHODS}

Two sets of data were used to construct the science-policy network interface regarding grassland management in China. The first set of data involved academic papers selected from the China Academic Journals Full_text Database (1951 onward) provided by the China Knowledge Resource Integrated Database (CNKI), which includes publications across a wide range of disciplines in China. The selection of scientists and their papers was based on a snowball sampling approach, a common method used "to identify who the relevant actors are when boundaries are not well defined" (Muñoz-Erickson and Cutts 2016:58). One important scientist in the field of grassland management was selected as the starting point for the search, with the scholars cited by this first scientist becoming candidates for the next round of searching. All selected papers, either in citing others or being referred to, had to contain the key words "grassland destruction," "grassland degradation," or "grassland conservation." To limit the sampling to major scholars, another criterion was added: to be regarded as academically important, a given paper must be cited by more than three other papers. This search generated a body of 173 papers written by 141 authors.

The second set of data involved articles from the official website of the Grassland Monitoring and Supervision Center of the Ministry of Agriculture, which provides official state opinions on grassland management. A total of 231 articles containing clear arguments on grassland degradation were extracted. This dataset included: (1) articles written by officials and (2) articles selected by the government to introduce scientific findings to the general public.

Out of the 173 academic papers and 231 official articles, 7 general categories of scholars and policymakers were identified: (1) geographers, (2) anthropologists, (3) ecologists, (4) engineers, (5) economists, (6) scholars from miscellaneous fields (others), and (7) officials. These scholars and policymakers expressed different understandings of the root causes and framed the problem in various ways. To reveal the underlying structures of this policy network, two types of networks, an actor-opinion network and an actor-institution network, were constructed. Such networks containing nodes belonging to different types (individuals versus opinions or institutions) are known as two-mode networks in social network analysis (Wasserman and Faust 1994).

For the actor-opinion networks, scholars and policymakers were linked to the opinions they ever presented in their papers or articles. The total number of opinions is greater than the total 
Table 1. Distribution of opinions among scholars and policymakers. Anth = anthropologists, Ecol = ecologists, Engi $=$ engineers, Geog = geographers, Econ = economists, and Official $=$ government officials.

\begin{tabular}{|c|c|c|c|c|c|c|c|c|}
\hline & Anth & Ecol & Engi & Geog & Econ & Official & Others & Total \\
\hline No. of people & 45 & 69 & 3 & 13 & 14 & 19 & 11 & 174 \\
\hline No. of opinion occurrence & 113 & 131 & 3 & 27 & 43 & 55 & 24 & 396 \\
\hline Opinions & \multicolumn{8}{|c|}{ Percentage of total occurrence } \\
\hline Climate change & 0.03 & 0.09 & 0.00 & 0.04 & 0.02 & 0.09 & 0.29 & 0.08 \\
\hline Agricultural expansion & 0.12 & 0.17 & 0.00 & 0.44 & 0.09 & 0.07 & 0.21 & 0.15 \\
\hline Overgrazing & 0.01 & 0.32 & 0.00 & 0.15 & 0.23 & 0.22 & 0.29 & 0.19 \\
\hline Lack of modernization & 0.01 & 0.24 & 1.00 & 0.07 & 0.07 & 0.27 & 0.00 & 0.14 \\
\hline Mining & 0.03 & 0.00 & 0.00 & 0.00 & 0.09 & 0.16 & 0.00 & 0.04 \\
\hline Overpopulation & 0.02 & 0.02 & 0.00 & 0.00 & 0.19 & 0.05 & 0.04 & 0.04 \\
\hline Urbanization & 0.02 & 0.00 & 0.00 & 0.00 & 0.00 & 0.02 & 0.04 & 0.01 \\
\hline Marketization & 0.06 & 0.05 & 0.00 & 0.00 & 0.12 & 0.04 & 0.00 & 0.05 \\
\hline Invasive species & 0.07 & 0.01 & 0.00 & 0.00 & 0.02 & 0.00 & 0.00 & 0.03 \\
\hline Deforestation & 0.01 & 0.02 & 0.00 & 0.19 & 0.07 & 0.00 & 0.13 & 0.04 \\
\hline Rodent damage & 0.00 & 0.02 & 0.00 & 0.00 & 0.00 & 0.04 & 0.00 & 0.01 \\
\hline Privatization/enclosure & 0.13 & 0.02 & 0.00 & 0.00 & 0.02 & 0.00 & 0.00 & 0.05 \\
\hline Loss of local knowledge & 0.35 & 0.02 & 0.00 & 0.07 & 0.02 & 0.00 & 0.00 & 0.11 \\
\hline Resedetarization & 0.14 & 0.02 & 0.00 & 0.04 & 0.05 & 0.00 & 0.00 & 0.05 \\
\hline Tree plantation & 0.00 & 0.01 & 0.00 & 0.00 & 0.00 & 0.02 & 0.00 & 0.01 \\
\hline Institutional overlap & 0.00 & 0.00 & 0.00 & 0.00 & 0.00 & 0.02 & 0.00 & 0.00 \\
\hline Top-down intervention & 0.00 & 0.02 & 0.00 & 0.00 & 0.00 & 0.00 & 0.00 & 0.01 \\
\hline Total & 1.00 & 1.00 & 1.00 & 1.00 & 1.00 & 1.00 & 1.00 & 1.00 \\
\hline
\end{tabular}

number of actors, as one person could present multiple opinions. Rather than assigning different weights to opinions based on the corresponding author's academic or political status, we weighed all the opinions equally. The actor-institution network was created in three steps. First, a network was drawn based on the citation relationship among the collected 173 academic papers. Scientists were abstracted as nodes, and their references to each other were modeled as directed links. The citation network allowed a general visualization of communications among scholars. In the second step, policymakers were added to this network. Third, officials and scholars were linked to their affiliated institutions. The research institutes and government agencies identified and included in the policy network were (1) the Ministry of Agriculture (MOA), (2) the State Ethnic Affair Commission (SEAC), (3) the State Forestry Administration (SFA), (4) the Chinese Academy of Sciences (CAS), (5) the Chinese Academy of Social Science (CASS), and (6) the universities and research institutions of Inner Mongolia (UIM). Unlike other research institutions, the group category of universities of Inner Mongolia was deliberately created to illustrate its potentially important role in the network. To reduce the complexity of the network, if a scholar was affiliated with two research institutions, only the first affiliation was considered. And if a scholar was affiliated with both a research institute and a government agency, only his/her affiliation with the government agency was considered and shown in the mapping. Because few Chinese scholars had double affiliations, this data cleaning had limited impact on the network analysis. It is worth noting that the list of institutions was extracted from the data rather than being defined ahead of time, which permitted the discovery of some hidden institutions that researchers may otherwise have excluded. Other researchers concerned with the boundaries of policy networks have also emphasized this point (Muñoz-Erickson and Cutts 2016).

\section{RESULTS}

An actor-opinion network and an actor-institution network were constructed (the use of colors and symbols are consistent among figures). The actor-opinion network mapped various framings of grassland problems as articulated by scientists and policymakers. All opinions were manually grouped into 17 categories (shown in Table 1). The most frequently discussed causes were agricultural expansion, overgrazing, lack of modernization, and loss of local knowledge. To give a dynamic picture, the changing numbers of opinions over years are shown in Table 2. From 1950 to 1990, agricultural expansion was the most frequently discussed cause, and it did not take long for overgrazing to become the dominant argument (2001-2010). For the four most frequently discussed causes, their numbers of occurrences reached the peak between the years 2001 and 2010, which indicates that during that period the grassland-degradation debate heated up.

Instead of unanimously agreeing on the root causes, different groups focused on different causes. As visually illustrated in Figure 1, ecologists and engineers talked more about agricultural expansion, overgrazing, and lack of modernization, whereas anthropologists concentrated their attention on sedentarization, privatization/enclosure, and loss of local knowledge. Those framings shared by most groups (such as climate change, agricultural expansion and marketization) are located in the center of the network. Officials concentrated on overgrazing, lack of modernization, and mining. The fact that officials and ecologists share a similar understanding of grassland problems indicates that the ecologist group received more official recognition than other disciplines. This ideological affiliation between officials and ecologists also suggests a large scientistpolicymaker cluster formed at the science-policy interface.

This mapping of opinions was followed by an examination of institutional affiliations. The visual depiction of the actor- 
Table 2. Changing opinions about grassland degradation over decades.

\begin{tabular}{|c|c|c|c|c|c|}
\hline & $1951 \sim 1990$ & $1991 \sim 2000$ & $2001 \sim 2010$ & $2011 \sim 2014$ & Total \\
\hline Climate change & 3 & 10 & 16 & 1 & 30 \\
\hline Agricultural expansion & 11 & 12 & 32 & 5 & 60 \\
\hline Overgrazing & 8 & 11 & 53 & 4 & 76 \\
\hline Lack of modernization & 8 & 4 & 29 & 14 & 55 \\
\hline Mining & 0 & 0 & 14 & 2 & 16 \\
\hline Overpopulation & 1 & 3 & 11 & 1 & 16 \\
\hline Urbanization & 0 & 0 & 3 & 1 & 4 \\
\hline Marketization & 0 & 1 & 17 & 2 & 20 \\
\hline Invasive species & 1 & 0 & 9 & 0 & 10 \\
\hline Deforestation & 4 & 5 & 5 & 1 & 15 \\
\hline Rodent damage & 1 & 2 & 2 & 0 & 5 \\
\hline Privatization/enclosure & 1 & 3 & 12 & 2 & 18 \\
\hline Loss of local knowledge & 3 & 7 & 28 & 7 & 45 \\
\hline Resedetarization & 1 & 5 & 11 & 4 & 21 \\
\hline Tree plantation & 0 & 0 & 1 & 1 & 2 \\
\hline Institutional overlap & 0 & 0 & 1 & 0 & 1 \\
\hline Top-down intervention & 0 & 0 & 0 & 2 & 2 \\
\hline
\end{tabular}

The numbers in the table represent the number of papers in which a certain cause was mentioned.

institution network (shown in Fig. 2) not only reveals an ecologistofficial cluster but also brings to light a two-pole structure-that is, with one group of nodes affiliated with the MOA and the CAS concentrated on one side and another group affiliated with CASS and SEAC on the other side. Between the two poles, there was a group that was constituted of individuals affiliated with the UIM. In social network analysis, this UIM group would be considered a bridge community that can potentially facilitate the exchange of knowledge and perspectives.

\section{DISCUSSION}

\section{Diverging scientific understandings}

Before analyzing the policy network as a whole, we should first consider the historical development of scientific interpretations of grassland problems. Scientists in the network have diverging opinions about what has happened to the grasslands. Closely examining these opinions revealed how different groups approach grassland problems from various perspectives and developed their own understanding of the problem. We limit our discussion to the four most frequently discussed causes, as shown in Table 1: (1) agricultural expansion, (2) overgrazing, (3) lack of modernization, and (4) loss of local knowledge.

Discussion about the possible negative impact of agricultural expansion can be traced back to the 1950s when a group of historical geographers ventured into the areas of desertification and developed a historical interpretation of local land degradation as a result of unwise agricultural expansion. In the late 1950s and the early 1960s, Renzhi Hou (Hou and Yu 1973) conducted one of the most prominent of these historical studies. Agricultural expansion in different historical periods has subsequently been discussed along similar lines. These scholars argue that the historical expansion of agricultural activities into grassland areas triggered a vicious cycle of soil erosion and environmental degradation, which eventually led to desertification in ecologically fragile regions. Scholars and policymakers have widely accepted this explanation, which is often referenced as a complementary cause to what other scholars believe to be the major cause of grassland degradation.
The overgrazing interpretation is primarily advanced by the ecologist group. By the 1960s, they built their own models and grassland classification systems (Wu and Loucks 1992). Ecologists used these classification systems to systematically evaluate grassland conditions and describe in a more standardized way the problem of grassland degradation (Wang 1992, Wu and Loucks 1992). They argue that grasslands experienced degradation as the number of livestock kept by local communities exceeded the grasslands' carrying capacity (Li and Ji 2004, Xu and Yang 2009). To control the problem, ecologists have called for more efforts in assessing the maximum number of livestock that can be raised on land units without causing irreversible degradation, as well as stricter government regulations that keep the total number under the calculated threshold (Williams 1996, Zhou et al. 2005, Zhang et al. 2014). This overgrazing interpretation has been called into question in part because of the difficulty of calculating the exact carrying capacity, especially in arid and semiarid regions, and also because it fails to factor in other socioeconomic variables (Williams 2002, Yeh 2005, Sayre 2008, Xu 2014).

The lack of modernization explanation has its roots in the perceived low productivity of traditional pastoralism, particularly discussed in the field of grassland systems engineering. Xuesen Qian, one of the most widely cited advocates of modernizing pastoralism, wrote an article in 1984 entitled "Grass, Grassland-based Industry, and the New Technological Revolution" ( $\mathrm{Li}$ 2002). In the article, Qian proposed some similarities between grass plantation and crop growing, arguing that grasslands had the same fundamental biological mechanism as agriculture, namely the conversion of solar energy into carbohydrates. Based on this similarity, Qian concluded that it was possible to improve the productivity of grasslands by copying the model of industrialized agriculture. This industrial model became an ideal venue for engineers to lament the low productivity of local pastoralism and frame the grassland problem as a product of a lack of modernity.

The lack of modernization often dovetailed with the discussion surrounding overgrazing because both arguments share the 
Fig. 1. Social network analysis of opinions among scientists and policymakers.

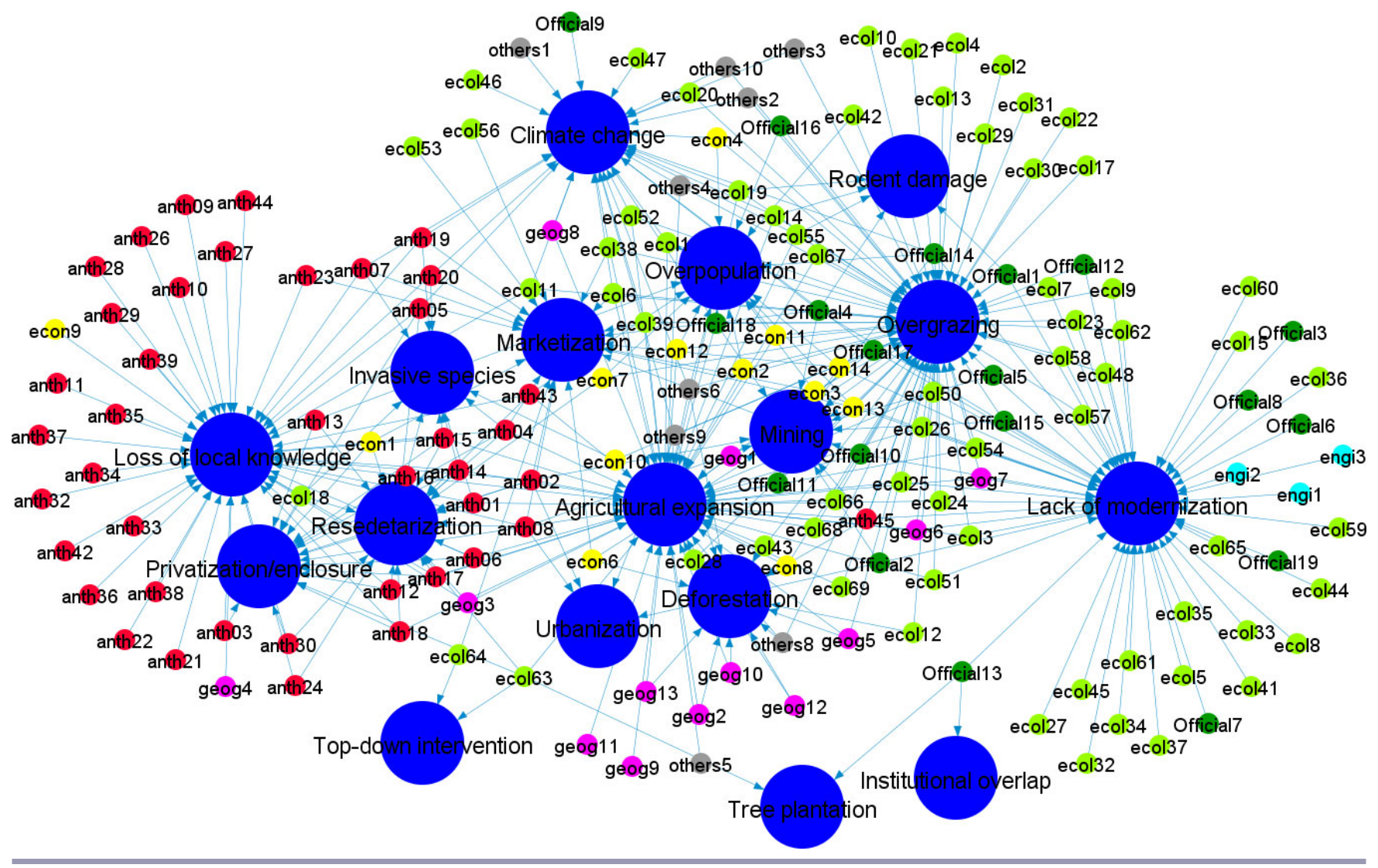

premise that local pastoralism should be transformed and modernized to incorporate the scientific calculation of carrying capacity as well as the efficient management of production activities. For this reason, many ecologists mentioned both of these causes in their papers (see Table 1).

Social scientists, and primarily anthropologists, who focused on cultural and social aspects of grassland problems, prioritized another cause, namely the loss of local knowledge. Historical changes, such as the privatization of grassland use rights, fencing and enclosure, and sedentarization, have transformed traditional herding patterns, communal relationships, and local adaptive strategies to the semiarid/arid environment. As a result of these changes, social scientists worry about the possible loss of local environmental knowledge (Erdenbuhe 2004, Zhang 2008, Xun 2011). Some even argue that the transformation of local practices and the absence of traditional regulating and coordinating systems serve as the root causes for the problems of overgrazing and grassland degradation (Zhang 2008, Luo 2013). The arguments of these Chinese scholars echo international criticism of land privatization and officials' lack of understanding of indigenous knowledge (Ostrom 1990, Williams 2002, Dove 2006).

From our analysis, we can tell that the four causes, agricultural expansion, overgrazing, lack of modernization, and loss of local knowledge, can be traced back to different disciplinary groups. Most scholars generally agree on the negative impacts of agricultural expansion on grasslands, although greater divergence surrounds the other three causes. In Figure 1, we can see that ecologists and engineers gravitate to one end of the network, clustering around overgrazing and lack of modernization; anthropologists, however, are clustered at the other end around loss of local knowledge. This mapping of opinions reveals the tensions inside of the scientific network.

One might expect that the lack of scientific consensus would prevent the government from taking a clear stance on this issue. On the contrary, instead of fully engaging with the scientific debate, policymakers showed no hesitation in siding with ecologists and engineers in the network. Official articles frequently discussed the causes of overgrazing and lack of modernization while largely ignoring alternative interpretations. The ideological affiliation among ecologists, engineers, and officials reflects strong scientist-policymaker connections inside the network.

\section{Affiliation, clustering, and polarization}

Scientists and policymakers are not only divided by their opinions, but are also separated by institutional affiliations. Connecting individuals with organizations in an integrated network helps to illustrate the development of the scientist-policymaker cluster and the emergence of dominant problem-framing positions within the science-policy interface.

In this case study, the policy network was partitioned into two groups, with ecologists, officials, the CAS, and the MOA at one 
Fig. 2. Clustering of scientists and policymakers in the network. MOA = Ministry of Agriculture, SEAC = State Ethnic Affair Commission, SFA $=$ State Forestry Administration, CAS $=$ Chinese Academy of Sciences, CASS $=$ Chinese Academy of Social Science, and UIM = the universities and research institutions of Inner Mongolia.

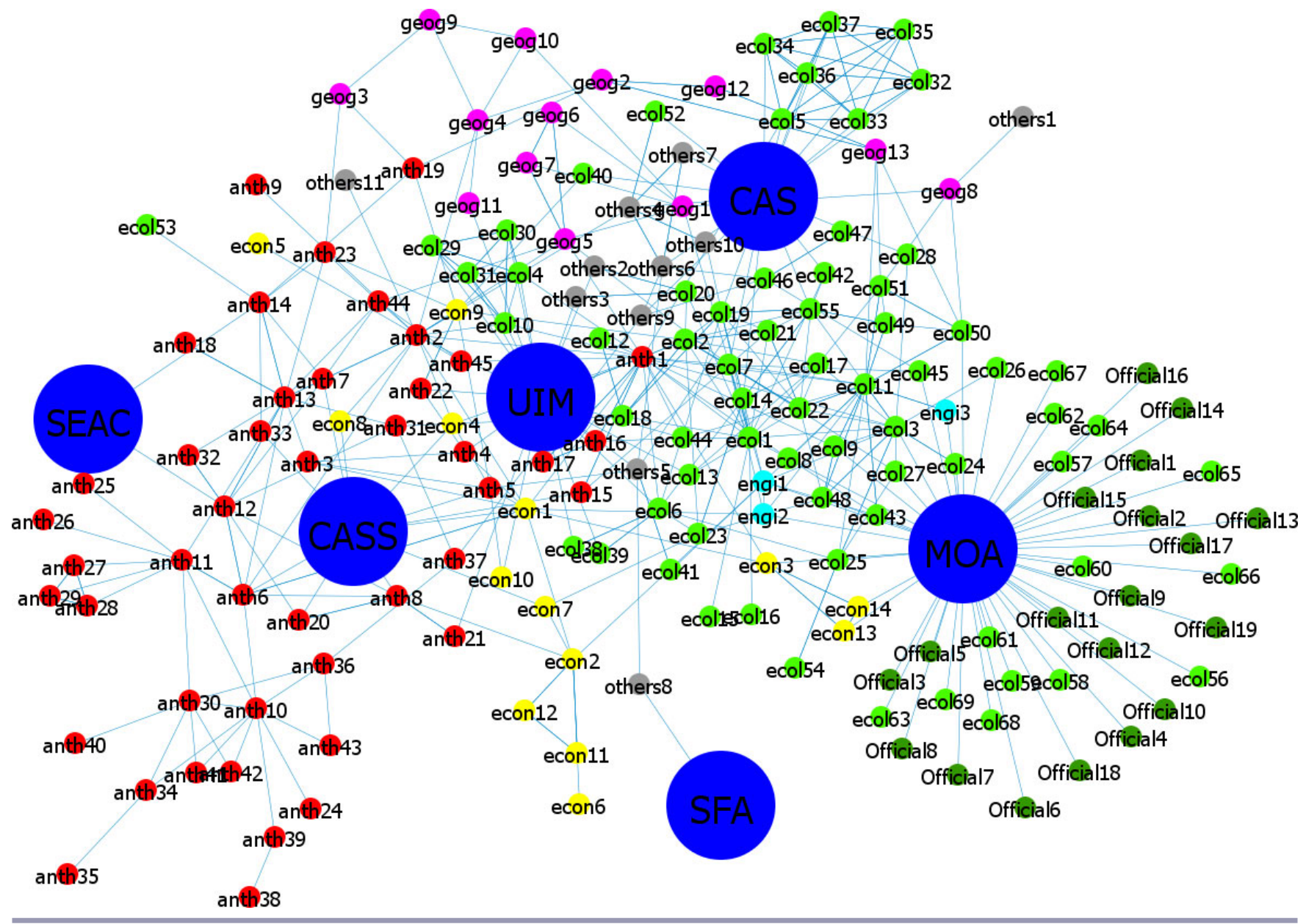

end and anthropologists, the CASS, and the SEAC at the other (see Fig. 2). At first glance, the CAS-CASS divide seems to indicate that the partition of the network follows the conventional cleavage between the natural and social sciences. Scholars of the two national think tanks seem to engage in limited interdisciplinary communication in the area of grassland management. Between the two groups, however, there was one bridge group, the UIM. Bridge groups linking different organizations and systems are considered to provide a valuable platform for collaborative research and knowledge sharing (Hahn et al. 2006, Olsson et al. 2007, Berkes 2009, Weiss et al. 2012). The presence of the UIM group in the network may indicate that a certain degree of interdisciplinary exchange takes place at the local level.

The involvement of government agencies, however, further complicates the picture. Three government institutions were included in the policy network, the MOA, SEAC, and SFA. The MOA administers both agricultural and pastoral activities, and as mentioned before, is the major institution in charge of comprehensive grassland management. The SEAC mainly addresses ethnic affairs. Its current responsibility is overseeing the implementation of national ethnic policies, conducting ethnic studies, and coordinating ethnic affairs with other socioeconomic activities. It should be noted that although grassland management is not explicitly included in its administrative responsibilities, the SEAC is one of the government institutions funding social science research in pastoral regions. The SFA has a relatively marginal role in the network because it mainly oversees forest management. Excluding the SFA as a marginal actor, the relationships between the MOA and SEAC seem to constitute the backbone of this policy network. Therefore, examining the MOA-SEAC dynamic became central to our analysis of the development of the policy network.

Underlying structure: an unbalanced institutional arrangement The MOA is the major institution for overseeing comprehensive grassland management and comprises 19 administrative bureaus, including the Animal Husbandry Bureau, which regulates grazing activities (Brown et al. 2008), and the Grassland Monitoring and Supervision Center, which monitors grassland conditions and implements grassland conservation policies. Although it plays an 
important role in grassland management, the MOA's capacity to regulate pastoralism and conserve grasslands is often compromised by its agriculture-centered perspective, as indicated in its name as the ministry of agriculture. It has a strong propensity to apply to pastoralism an agricultural managerial philosophy, which emphasizes the importance of intensive production, also known as industrial agriculture. In addition, the MOA advocates for the grassland industry (also known as industrial pastoralism), which is supported by grassland engineers (Li 2010).

Regarding the SEAC, although grassland management is not explicitly included in its administrative responsibilities, it has historically influenced the economic policies in ethnic regions (including Inner Mongolia and Tibet) and therefore has indirectly affected the management of grasslands and pastoralism. In the 1950 s, as indicated in the minutes of SEAC's Third Extended Meeting, its managerial goals included "carrying out cautious intervention and facilitating stable progress" and "revitalizing animal husbandry production" (People's Publishing House 1958:100-112).

A balanced administrative system might have become possible if the MOA and SEAC enjoyed relatively equal authority in grassland management. However, the SEAC has been limited to a supplementary role by the central government since the late 1980s. In the outlines for the National Working Conference on Pastoral Regions, issued in 1987, the MOA (at that time the Ministry of Agriculture, Pastoralism and Fisheries), rather than the SEAC, was designated as the primary agency for overseeing grassland management and pastoral development:

In order to enhance and coordinate the economic administration of pastoral regions, the conference decided that, while in collaboration with the SEAC and supported by other bureaus, the Ministry of Agriculture, Pastoralism and Fisheries [later changed into the MOA] will be the leading institution to conduct research and design economic development plans for pastoral regions and to lead, supervise, and check the fiscal conditions and the implementation of guidelines and policies in pastoral regions.

This institutional arrangement has changed little since 1987. The MOA remains the leading institution for research into grasslandmanagement policies. The creation of an unbalanced institutional system has had a long-term effect on the framing of grassland problems. In contrast to the sector-centered MOA, the SEAC embraces a more holistic approach toward managing pastoral regions. Instead of limiting its focus to economic development, the SEAC has historically emphasized the importance of traditional culture and practices in pastoral regions. The MOA has eschewed such a holistic approach, which has discouraged an interdisciplinary discussion of grassland problems. Moreover, the SEAC has financially supported an intellectual base, including anthropologists and other social scientists. The limited role of the SEAC in the field of grassland management suggests a constrained funding source for social scientists concerned with grassland-degradation issues, which in turn affects the power of social scientists in the policy network.

\section{Political constrains on problem framing}

The preexisting institutional arrangement, namely the power imbalance between the MOA and SEAC, has greatly affected the clustering inside the policy network and the framing of grassland problems. The dominance of the MOA in the administrative system is reflected in the balance of scientific arguments inside the policy network. Although four major interpretations of grassland degradation have developed over time, they do not receive the same degree of official recognition. The MOA, because of its interests in the industrialization and modernization of local pastoralism, tends to argue that local traditional practices are less productive and more destructive to grassland environments. This political orientation has led officials in the MOA to selectively endorse certain framings, namely overgrazing and lack of modernity, that support their political beliefs and to form a strong scientist-policymaker cluster with ecologists and engineers. This process reinforces a dynamic cycle of research activities, affiliations, and policy development. Political affiliation and clustering, rather than a static state, reflect an ongoing process of active connection and network evolution. Those in a different ideological camp, on the other hand, have much less political power. The limited authority of the SEAC in the administrative hierarchy after 1987 has led to the weak political influence of the anthropologist-SEAC cluster and subsequently the marginalization of their framings of the problem of grassland degradation. As a result, the problems of overgrazing and lack of modernity enjoy more time in the spotlight, whereas the problem of loss of local knowledge does not receive enough political support.

Scientific interpretations of grassland degradation circulate inside the policy network, with discussions among scientists from different disciplines and subfields helping to generate a repertoire of concepts and ideas that have enriched a popular understanding of grassland problems. An array of factors, however, have mediated the introduction of these scientific ideas into the policy domain, including the ways that scientists reach consensus, how scientists and policymakers communicate and reconcile their arguments, and the balance of power relations between institutions. In this case study, the dominance of the MOA and the strong ecologist-official-MOA cluster has excluded from the policy domain the discussion of loss of local knowledge. Despite the fact that the science-policy interactions are dynamic and fluid rather than static, the science-policy interactions in this case study are inevitably circumscribed by the underlying political structure of the policy network.

The framing of grassland problems based on overgrazing and lack of modernity has gradually been incorporated into policymaking after the year 2000, as shown in Table 3. Starting from the year 2003, the Chinese government announced the implementation of a series of grazing bans in the Notice on the Task of Returning Pastures to Grassland. These policies included four major regulations: year-round or seasonal grazing bans, demarcation of fallow fields, rotation grazing, and livestock confinement (Dong et al. 2007). The validity of the overgrazing argument was reinforced in the following decade by the continuous issuing of policies and national plans made of similar scientific framings. So is the lack of modernization argument. Similar framing can be constantly observed in official documents concerned with grassland conservation and agricultural development, including the Master Plan on National Grassland Conservation, Construction and Utilization issued in 2007, the Plan for Ecological Protection and Construction (2013-2020) in 2013, and the National Plan for Agricultural Modernization (2016-2020) in 2016. The modernization of local pastoralism is 
Table 3. National policies and related scientific framings.

\begin{tabular}{|c|c|c|}
\hline Year & Official document & Related framing \\
\hline 2003 & Notice on the Task of Returning Pastures to Grassland & Overgrazing \\
\hline 2005 & Opinion on the Further Implementation of Returning-pastures-to-grassland Policy & Overgrazing \\
\hline 2007 & Master Plan on National Grassland Conservation, Construction and Utilization & $\begin{array}{c}\text { Agricultural expansion } \\
\text { Lack of modernization } \\
\text { Overgrazing }\end{array}$ \\
\hline 2011 & Opinion on Improving Returning-pastures-to-grassland Policy & Overgrazing \\
\hline 2013 & Plan for Ecological Protection and Construction (2013 - 2020) & $\begin{array}{c}\text { Agricultural expansion } \\
\text { Lack of modernization } \\
\text { Overgrazing } \\
\text { Rodent damage }\end{array}$ \\
\hline 2016 & Working Plan on Establishing Grassland Conservation Regime & $\begin{array}{c}\text { Agricultural expansion } \\
\text { Lack of modernization } \\
\text { Overgrazing }\end{array}$ \\
\hline 2016 & $\begin{array}{l}\text { Notice of the State Council of the People's Republic of China on Issuing the National } \\
\text { Plan for Agricultural Modernization (2016-2020) }\end{array}$ & $\begin{array}{c}\text { Lack of modernization } \\
\text { Overgrazing } \\
\text { Rodent damage }\end{array}$ \\
\hline
\end{tabular}

widely promoted in most regions, with the introduction of grass plantation, exotic species, and modern livestock confinement (Yeh 2005, Li and Li 2012). Local pastoralism is increasingly evaluated against a set of modern standards centered on productivity and efficiency. Confined by these dominant paradigms, the government has failed to acknowledge other social and cultural aspects of pastoralism. Their narrowly focused intervention has not only achieved limited environmental results but has also led to greater tension between the government and local communities.

This study links the policy network with a historical selfreinforcing process that has led to the development of the power imbalance. Our explanation focuses on the initial events that put the framing of grassland problems on a certain trajectory and the social mechanism (in this case, a process of clustering and polarization) that has reinforced the trajectory. This analytical approach draws this study closer to path dependence discussions. Due to limitation of available data, our work only provided a snapshot view of the network and advanced the first step to understanding the dynamic interactions among individuals and institutions at a macro level. Revealing these mechanisms will eventually help us to develop hypotheses about "the kind of events or processes that might generate major subsequent change points" (Pierson 2004:52). The power imbalance in the network helps to explain why certain environmental arguments are extremely persistent. It also points us to a direction of reform that could potentially disrupt the mechanism of reproduction and offers an instrument for future change.

\section{CONCLUSION}

The analysis of the policy network reveals the political forces that affect the framing of environmental problems, which are determined by the science-policy interactions at both the individual and organizational levels. Power dynamics at the organizational level, as a result of the existing institutional arrangement, may give rise to the formation of a particular scientist-policymaker cluster in the policy network. By increasing the attractiveness of certain arguments while suppressing other alternatives, the scientist-policymaker cluster may set the limits for the development of alternative framings and policies. In this case study, the application of social network analysis allowed us to untangle the multilayered structure of the policy network and bring to light the connections between the political structure of policy network and the framing of environmental problems. Since the 1980s, the arrangement of the administrative system has paved the way for the formation of an ecologist-official cluster in the network as well as the dominance of certain ways of framing the problem of grassland degradation. This study stresses the importance of understanding the political structure of a policy network to enhance science-policy integration, facilitate meaningful institutional changes, and achieve the sustainable management of natural resources.

Responses to this article can be read online at: http://www.ecologyandsociety.org/issues/responses. $\mathrm{php} / 9321$

\section{LITERATURE CITED}

Bäckstrand, K. 2003. Civic science for sustainability: reframing the role of experts, policy-makers and citizens in environmental governance. Global Environmental Politics 3(4):24-41. http://dx. doi.org/10.1162/152638003322757916

Benford, R. D., and D. A. Snow. 2000. Framing processes and social movements: an overview and assessment. Annual Review of Sociology 26:611-639. http://dx.doi.org/10.1146/annurev.soc.26.1.611

Berkes, F. 2009. Evolution of co-management: role of knowledge generation, bridging organizations and social learning. Journal of Environmental Management 90(5):1692-1702. http://dx.doi. org/10.1016/j.jenvman.2008.12.001

Bodin, Ö., and B. I. Crona. 2009. The role of social networks in natural resource governance: what relational patterns make a difference? Global Environmental Change 19(3):366-374. http:// dx.doi.org/10.1016/j.gloenvcha.2009.05.002 
Brown, C. G., S. A. Waldron, and J. W. Longworth. 2008. Sustainable development in Western China: managing people, livestock and grasslands in pastoral areas. Edward Elgar, Cheltenham and Northhampton, UK.

Cheon, A., and J. Urpelainen. 2013. How do competing interest groups influence environmental policy? The case of renewable electricity in industrialized democracies, 1989-2007. Political Studies 61(4):874-897. http://dx.doi.org/10.1111/1467-9248.12006

David, P. A. 1994. Why are institutions the 'carriers of history'?: path dependence and the evolution of conventions, organizations and institutions. Structural Change and Economic Dynamics 5 (2):205-220. http://dx.doi.org/10.1016/0954-349X(94)90002-7

Dong, S. K., H. W. Gao, G. C. Xu, X. Y. Hou, R. J. Long, M. Y. Kang, and J. P. Lassoie. 2007. Farmer and professional attitudes to the large-scale ban on livestock grazing of grasslands in China. Environmental Conservation 34(4):349. http://dx.doi.org/10.1017/ $\underline{\mathrm{S} 0376892907004420}$

Dove, M. R. 2006. Indigenous people and environmental politics. Annual Review of Anthropology 35(1):191-208. http://dx.doi. org/10.1146/annurev.anthro.35.081705.123235

Entman, R. M. 1993. Framing: toward clarification of a fractured paradigm. Journal of Communication 43(4):51-58. http://dx.doi. org/10.1111/j.1460-2466.1993.tb01304.X

Erdenbuhe. 2004. A major cause for the desertification of grasslands. Journal of Inner Mongolia University 36(2):81-85.

Haas, P. M. 1992. Introduction: epistemic communities and international policy coordination. International Organization 46 (1):1-35. http://dx.doi.org/10.1017/S0020818300001442

Hahn, T., P. Olsson, C. Folke, and K. Johansson. 2006. Trustbuilding, knowledge generation and organizational innovations: the role of a bridging organization for adaptive comanagement of a wetland landscape around Kristianstad, Sweden. Human Ecology 34(4):573-592. http://dx.doi.org/10.1007/s10745-006-9035$\underline{\mathrm{Z}}$

Harris, R. B. 2010. Rangeland degradation on the QinghaiTibetan plateau: a review of the evidence of its magnitude and causes. Journal of Arid Environments 74(1):1-12. http://dx.doi. org/10.1016/j.jaridenv.2009.06.014

Hou, R., and W. Yu. 1973. Archaeological discovery and the changes of geographical environment in Ulan Buh Desert. Archaeology 2:1-12.

Jasanoff, S., and B. Wynne. 1998. Science and decision making. Pages 1-87 in S. Rayner and E. L. Malone, editors. Human choice and climate change: an international assessment. Battelle, Columbus, Ohio, USA.

Kenis, P., and V. Schneider. 1991. Policy networks and policy analysis: scrutinizing a new analytical toolbox. Pages 25-59 in B. Marin and R. Mayntz, editors. Policynetworks: empirical evidence and theoretical considerations. Westview, Boulder, Colorado, USA.

Kolås, Å. 2014. Degradation discourse and green governmentality in the Xilinguole grasslands of Inner Mongolia. Development and Change 45(2):308-328. http://dx.doi.org/10.1111/dech.12077
Li, W., and Y. Li. 2012. Managing rangeland as a complex system: How government interventions decouple social systems from ecological systems. Ecology and Society 17(1):9. http://dx.doi. org/10.5751/ES-04531-170109

Li, Y. 2002. Qian Xuesen's epoch-making contribution to the initiation of knowledge-intensive grass industry. Engineering Science 4(1):251.

Li, Y. 2010. Learning and implementing Deng Xiaoping's theories of modern agriculture with Chinese characteristics. Pratacultural Science 27(12):1-4.

Li, Y., and J. Ji. 2004. Assessment of the productivity and livestock carrying capacity of Inner Mongolia grassland by regional scale modeling. Journal of Natural Resources 19(5):610-616.

Luo, S. 2013. Cultural erosion and the deterioration of grasslands in Inner Mongolia. Modern Anthropology 1:10-16. http://dx.doi. org/10.12677/MA.2013.12003

Mahoney, J., and K. Thelen. 2009. Explaining institutional change: ambiguity, agency, and power. Cambridge University Press, Cambridge, UK. http://dx.doi.org/10.1017/CBO9780511806414

Muñoz-Erickson, T. A., and B. B. Cutts. 2016. Structural dimensions of knowledge-action networks for sustainability. Current Opinion in Environmental Sustainability 18:56-64. http:// dx.doi.org/10.1016/j.cosust.2015.08.013

Nisbet, M. C., and C. Mooney. 2007. Framing science. Science 316(5821):56. http://dx.doi.org/10.1126/science.1142030

Offermans, A., and P. Glasbergen. 2015. Boundary work in sustainability partnerships: an exploration of the Round Table on Sustainable Palm Oil. Environmental Science and Policy 50:34-45. http://dx.doi.org/10.1016/j.envsci.2015.01.016

Olsson, P., C. Folke, V. Galaz, T. Hahn, and L. Schultz. 2007. Enhancing the fit through adaptive co-management: creating and maintaining bridging functions for matching scales in the Kristianstads Vattenrike Biosphere Reserve Sweden. Ecology and Society 12(1):28. http://dx.doi.org/10.5751/ES-01976-120128

Ostrom, E. 1990. Governing the commons: the evolution of institutions for collective action. Cambridge University Press, Cambridge, UK.

People's Publishing House. 1958. Proceeding of ethnic policies: volume one. People's Publishing House, Beijing, China.

Pierson, P. 2000. Increasing returns, path dependence, and the study of politics. American Political Science Review 94 (2):251-267. http://dx.doi.org/10.2307/2586011

Pierson, P. 2004. Politics in time: history, institutions, and social analysis. Princeton University Press, Princeton, New Jersey, USA. http://dx.doi.org/10.1515/9781400841080

Pregernig, M. 2014. Framings of science-policy interactions and their discursive and institutional effects: examples from conservation and environmental policy. Biodiversity and Conservation 23(14):3615-3639. http://dx.doi.org/10.1007/ $\underline{\text { s10531-014-0806-3 }}$

Rose, R. 1991. Introduction: lesson-drawing across nations. Journal of Public Policy 11(1):1-2. http://dx.doi.org/10.1017/ $\underline{\mathrm{S} 0143814 \mathrm{X} 00004906}$ 
Sayre, N. F. 2008. The genesis, history, and limits of carrying capacity. Annals of the Association of American Geographers 98 (1):120-134. http://dx.doi.org/10.1080/00045600701734356

Schoon, M. 2013. Governance in transboundary conservation: how institutional structure and path dependence matter. Conservation and Society 11(4):420-428. http://dx.doi. org/10.4103/0972-4923.125758

State Bureau of Environment Protection (SBEP). 2006. 2005 Report on environmental conditions in China. State Bureau of Environment Protection, Beijing, China.

Stone, D. 2002. Using knowledge: the dilemmas of 'bridging research and policy'. Compare 32(3):285-296. http://dx.doi. org/10.1080/0305792022000007454

Thelen, K. 2004. How institutions evolve: the political economy of skills in Germany, Britain, the United States, and Japan. Cambridge University Press, Cambridge, UK. http://dx.doi. org/10.1017/CBO9780511790997

Wang, Z. 1992. Central Inner Mongolia. Pages 85-92 in National Research Council, editor. Grasslands and grassland sciences in northern China. National Academy Press, Washington, D. C., USA.

Wasserman, S., and K. Faust. 1994. Social network analysis: methods and applications. Cambridge University Press, Cambridge, UK. http://dx.doi.org/10.1017/CBO9780511815478

Weiss, K., M. Hamann, M. Kinney, and H. Marsh. 2012. Knowledge exchange and policy influence in a marine resource governance network. Global Environmental Change 22 (1):178-188. http://dx.doi.org/10.1016/j.gloenvcha.2011.09.007

Williams, D. 1996. Grassland enclosures: catalyst of land degradation in Inner Mongolia. Human Organization 55 (3):307-313. http://dx.doi.org/10.17730/humo.55.3.u46ht013r361668t

Williams, D. M. 2002. Beyond great walls: environment, identity, and development on the Chinese grasslands of Inner Mongolia. Stanford University Press, Stanford, California, USA.

Wu, J., and O. L. Loucks. 1992. Xilingele grassland. Pages 67-84 in National Research Council, editor. Grasslands and grassland sciences in northern China. National Academy Press, Washington, D. C., USA.

Xu, B., and X. C. Yang. 2009. Calculation of grass production and balance of livestock carrying capacity in rangeland region of northeast China. Geographical Research 28:402-408.

Xu, M. 2014. A review of grassland carrying capacity: perspective and dilemma for research in China on forage-livestock balance. Acta Prataculture Sinica 23(5):321-329.

Xun, L. 2011. Coexistence with uncertainty: indigenous knowledge of steppe nomads. Academia Bimestris 3:18-29.

Ye, Y., and X. Fang. 2013. Boundary shift of potential suitable agricultural area in farming-grazing transitional zone in northeastern China under background of climate change during 20th century. Chinese Geographical Science 23(6):655-665. http:// dx.doi.org/10.1007/s11769-013-0638-1
Yeh, E. T. 2005. Green governmentality and pastoralism in western China: "converting pastures to grasslands." Nomadic Peoples 9(1):9-30. http://dx.doi.org/10.3167/082279405781826164

Yu, L., and K. N. Farrell. 2013. Individualized pastureland use: responses of herders to institutional arrangements in pastoral China. Human Ecology 41(5):759-771. http://dx.doi.org/10.1007/ s10745-013-9580-1

Zhang, Q. 2012. The dilemma of conserving rangeland by means of development: exploring ecological resettlement in a pastoral township of Inner Mongolia. Nomadic Peoples 16(1):88-115. http://dx.doi.org/10.3167/np.2012.160108

Zhang, W. 2008. An environmental anthropology approach to grassland desertification: village B in Northern Maowusu Desert as an example. Chinese Journal of Sociology 28(4):187-205.

Zhang, Y. J., X. Q. Zhang, X. Y. Wang, N. Liu, and H. M. Kan. 2014. Establishing the carrying capacity of the grasslands of China: a review. Rangeland Journal 36(1):1-9. http://dx.doi. org/10.1071/RJ13033

Zhou, H., X. Zhao, Y. Tang, S. Gu, and L. Zhou. 2005. Alpine grassland degradation and its control in the source region of the Yangtze and Yellow rivers, China. Grassland Science 51 (3):191-203. http://dx.doi.org/10.1111/j.1744-697X.2005.00028.x 